Pecvnia, 5 (2007), pp. 1-15

\title{
El valor jurídico de un libro: Don Quixote de la Mancha (Con Epílogo sobre su precio originario y las economías de una cátedra universitaria hace trescientos años)
}

\author{
Germán José María Barreiro González \\ gjbarg@unileon.es \\ Universidad de León \\ Derecho del Trabajo y de la Seguridad Social \\ Fac. de Derecho \\ Campus de Vegazana, $\mathrm{s} / \mathrm{n}$ \\ 24071 León (España)
}

Miguel de Cervantes Saavedra, se inscribe en la nómina de los literatos clásicos y universales que combinaron de manera magistral la Literatura y el Derecho. De todos es conocida la omnipresencia de lo jurídico en la obra de Cervantes. Pero la que muestra una irrupción extensa del autor en el mundo del Derecho es la conocida popularmente como "Don Quixote de La Mancha": Derechos de la persona (la defensa de la vida, la libertad, la igualdad natural de los hombres); Derecho de Gentes (la concepción de la guerra y la paz, la humanización de la guerra); Monarquía, Estados y República; Gobierno y Administración de justicia (fundamentalmente la tarea de Sancho Panza como Gobernador de la Insula de Barataria); Derecho Penal (delitos y penas, antropología criminal); Derecho Privado (propiedad, responsabilidad por daños, familia); y
Miguel de Cervantes Saavedra is a classic and universal writer who wisely combined Literature and Law. It is very well known that legal aspects are present in Cervantes' works, mainly in Don Quixote: Rights of the person (life defence, freedom, natural equality of men); lus Gentium (the conception of war and peace, war humanization); Monarchy, States and Republic; Government and Justice Administration (mainly Sancho Panza's task as governor of the "Insula de Barataria"); Criminal Law (criminal offences and sentences, criminal anthropology); Private Law (property, damage responsibility, family); and Labour Law (jobs and services of the time, legal relationship 
Derecho del Trabajo (trabajos, oficios y servicios de la época, la relación jurídica entre don Quijote y Sancho). A modo de Epílogo, la financiación de los libros de una cátedra universitaria y el coste al público, en la época, de la Novela inmortal.

Palabras clave: Derechos de la persona. Guerra y Paz. Gobierno, Administración de Justicia. Derecho Penal, Privado y del Trabajo. between don Quixote and Sancho). As an Epilogue, the financing of books of a University chair and the public cost of the time of the inmortal Novel are offered.

Key words: Rights of the person; War and Peace; Government, Justice Administration; Criminal Law; Private Law; Labour Law.

\section{PRÓLOGO}

Desde el alumbramiento del Quijote hace ya más de 400 años no han dejado de sorprender los conocimientos científicos, médicos y de ingeniería de Cervantes. El Quijote es un excepcional muestrario tipológico, cultural y sociológico válido para todas las épocas. Pero también encierra notables conocimientos de Medicina, Astronomía, Farmacia, Matemáticas, Veterinaria o Ingeniería. Asimismo de Derecho. Miguel de Cervantes Saavedra, se inscribe en la nómina de los literatos clásicos y universales que combinaron de manera magistral la Literatura y el Derecho. La omnipresencia de lo jurídico en la obra literaria de Cervantes ha llevado siempre a los estudiosos a preguntarse si Cervantes fue o no jurisperito. Pero precisamente la obra que muestra una irrupción extensa del autor en el mundo del Derecho es la conocida popularmente como don Quijote de la Mancha, publicada su primera parte en 1605 y la segunda en $1615^{*}$.

La Obra está preñada de acciones, actuaciones, ideas, diálogos y discursos de infinidad de personajes que por ella desfilan -principalmente don Quijote y Sancho Panza- en relación con el Derecho, con una prosa y poética solemne, cómica, triste, irónica o satírica según los casos, pero siempre viva. La selección de sus pasajes que luego se dirán y que son objeto de comentario, se impone a la vista de su

Para la realización de este trabajo he manejado la magnífica Edición de Don Quijote de la Mancha del Instituto Cervantes. Crítica. Dirigida por Francisco Rico con la colaboración de Joaquín Forradellas y estudio preliminar de Fernando Lázaro Carreter. Biblioteca Clásica. Barcelona 1998, vol. 50, que me ha sido de gran utilidad para comprender vocablos y expresiones en su sentido histórico y actual. En cursiva se ponen solamente los textos literales de la Novela; palabras, expresiones o vocablos de la misma. Las citas van con numeración romana para hacer referencia a la parte primera o segunda de la obra (I y II) y a continuación, con numeración arábiga, el capítulo correspondiente. 
magnitud y calidad y responde tanto a un interés jurídico como literario indisolublemente unidos, fruto de la sola y exclusiva subjetividad entendida como opción personal, atenta desde luego a lo que cada uno descubre con su lectura pero sin llegar al extremo expresado por Unamuno en el Prólogo a "Del sentimiento trágico de la vida" (1913): "¿Qué me importa lo que Cervantes quiso o no quiso poner allí y lo que realmente puso? Lo vivo es lo que yo allí descubro, pusiéralo o no Cervantes".

La señalada opción personal no ignora, en definitiva, que La Obra - que dicho sea de paso, está constantemente salpicada de rico vocabulario y terminología jurídica con formulación precisa- contiene otros múltiples episodios y sucesos de interés y relevancia jurídica que, por conocidos, ahorro al lector su referencia y que el propio lector bien podría haber escogido en lugar de los que aquí lo han sido, como bien podría haber estructurado el Sumario de forma distinta a la vista de su opción jurídico-literaria.

\section{DERECHOS DE LA PERSONA}

La defensa de la vida, dice don Quijote, que es de ley natural y divina es una de las cuatro cosas, por las que se han de tomar las armas (II, 27). En otro pasaje le dice Sancho a don Quijote: en lo que tocare a defender mi persona... las [leyes] divinas y humanas permiten que cada uno se defienda de quien quisiere agraviarle $(I, 8)$. Incluso cuando este "quien" es don Quijote, su amo y señor. Así, discutiendo Sancho con don Quijote que trata de azotarle, el escudero en uso de su legítima defensa derriba al caballero al suelo y este le dice: ¿Cómo traidor? ¿Contra tu amo y señor te desmandas?... Y Sancho le responde: ni quito ni pongo rey... sino ayúdome a mí, que soy mi señor (II, 60).

Se remarca el carácter inalienable de la libertad: non bene pro toto libertas venditur auro [I, Prólogo; (no existe oro suficiente para pagar la venta de la libertad)]. Así, don Quijote volviéndose a Sancho le dijo: La Libertad, Sancho, es uno de los más preciosos dones que a los hombres dieron los cielos; con ella no pueden igualarse los tesoros que encierra la tierra ni el mar encubre; por la libertad así como por la honra se puede y debe aventurar la vida, y, por el contrario, el cautiverio es el mayor mal que puede venir a los hombres (II, 58). En efecto, gracias sean dadas a Dios - dijo el cautivo- por tantas mercedes como le hizo, porque no hay en la tierra, conforme mi parecer, contento que se iguale a alcanzar la libertad perdida (I, 39). 
Sin embargo la recuperada libertad debe ejercerse con dignidad; de ahí la critica de don Quijote: no es bien que se haga... lo que suelen hacer los que ahorran y dan libertad a sus negros cuando ya son viejos y no pueden servir, y echándoles de casa con títulos de libres los hacen esclavos de la hambre, de quien no piensan ahorrarse sino con la muerte (II, 24).

Con frecuencia se alude a las patentes desigualdades derivadas del estado o condición social, laboral o personal o por circunstancias económicas: señores, caballeros, hidalgos, villanos, vasallos, esclavos, mujeres, pobres y ricos... (I, 10, 15, 24, 33; II, 6, 24, 42, 43, 45, $49,50 \ldots)$.

Sin embargo la concepción sobre la igualdad natural de los hombres se afirma con rotundidad en algunos pasajes. Así, don Quijote le dice a Sancho, que no es un hombre más que otro, si no hace más que otro $(\mathrm{I}, 18)$ y le aconseja antes de ser Gobernador de la Insula de Barataria: Haz gala [no te preocupes] Sancho, de la humildad de tu linaje y no te desprecies de decir que vienes de labradores, porque viendo que no te corres [avergüenzas], ninguno se pondrá a correrte, y préciate más de ser humilde virtuoso que pecador soberbio. Innumerables son aquellos que de baja estirpe nacidos, han subido a la suma dignidad pontificia e imperatoria... Si... te precias de hacer hechos virtuosos, no hay para que tener envidia a los que padres y agüelos tienen príncipes y señores, porque la sangre se hereda y la virtud se aquista [conquista] y la virtud vale por sí sola lo que la sangre no vale (II, 42).

\section{DERECHO DE GENTES: SOBRE LA GUERRA Y LA PAZ}

La concepción cervantina sobre la guerra y la paz se pone de manifiesto por boca de don Quijote. Se pregunta éste sobre la preeminencia de las armas contra las letras, a esto responde él mismo diciendo que sin las armas las leyes no se podrían sustentar..., porque con las armas se defienden las repúblicas, se conservan los reinos, se guardan las ciudades, se aseguran los caminos... si por ellas no fuese, las repúblicas, los reinos, las monarquías, las ciudades, los caminos... estarían sujetos al rigor y a la confusión que trae consigo la guerra el tiempo que dura y tiene licencia de usar de sus privilegios y de sus fuerzas. 
La señala preeminencia está sin embargo gobernada por un principio irrenunciable para don Quijote unido indisolublemente a su personalidad, la consecución de la paz: Es el fin y paradero de las letras... humanas... entender y hacer que las buenas leyes se guarden. Fin por cierto generoso y alto y digno de grande alabanza, pero no de tanta como merece aquel a que las armas atienden, las cuales tienen por objeto y fin la paz; pues, en efecto, prosigue diciendo don Quijote, la paz es el mayor bien que los hombres pueden desear en esta vida... Esta paz es el verdadero fin de la guerra, que lo mesmo es decir armas que guerra (I, 37 y 38). Una guerra que los varones prudentes [y] las repúblicas bien concertadas están legitimados para emprender, por defender la fé católica... por defender su vida... en defensa de su honra, de su familia y hacienda... en servicio de su rey en la guerra justa y... en defensa de su patria (II, 27).

Se contempla la idea de la "humanización" de la guerra y las condiciones y reglas en que debe realizarse. Así dice don Quijote que la guerra también tiene sus leyes y está sujeta a ellas (I, 38; asimismo en II, 62) y arremete contra la espantable furia de aquestos endemoniados instrumentos de la artillería a cuyo inventor tengo para mí que en el infierno se le está dando el premio de su diabólica invención (I, 38).

\section{MONARQUÍA, ESTADOS Y REPÚBLICA}

En diversos pasajes se trasluce la concepción absolutista de la monarquía; el rey representa cuando no se identifica con la misma justicia: allá van leyes, do quieren reyes (I, Prólogo); el propio Sancho sentencia ante don Quijote: advierta vuestra merced... que la justicia que es el mesmo rey... (I, 22).

Característica es también su alcance o sentido patrimonial. Así, el bachiller Sansón Carrasco y el paje estaban confusos y no acababan de atinar qué sería aquello del Gobierno de Sancho, y más de una ínsula, siendo todas o las más que hay en el mar Mediterráneo de su Majestad (II, 50). El referido carácter patrimonial aparece en ocasiones ligado con la expresión estado o estados que en efecto se relaciona con el concepto de soberanía como equivalente a posesiones de reinos o dominios, incluso de naturaleza feudal. Dice al respecto don Quijote: su Majestad ha hecho como prudentísimo guerrero en proveer sus estados con tiempo, porque no le halle desapercibido el enemigo (II, 1). Id hermano Panza [dijo la 
duquesa], y decid a vuestro señor [don Quijote], que él sea el bien llegado y el bien venido a mis estados (II, 30).

Desde una óptica en cierto modo paternalista, debe el rey protección y atención para con sus súbditos. Uno de los mayores trabajos que los reyes tienen, entre otros muchos [dice don Quijote] es el de estar obligados a escuchar a todos y a responder a todos (II, 6). A su vez, los súbditos deben obediencia y lealtad a su rey. Así, un mancebo presto a convertirse en soldado le dice a don Quijote: $Y$ más quiero tener por amo y por señor al rey, y servirle en la guerra, que no a un pelón en la Corte. El propósito del mancebo es alabado por el Caballero diciéndole: no hay otra cosa en la tierra más honrada y de más provecho que servir a Dios, primeramente, y luego a su rey y señor natural, especialmente en el ejercicio de las armas (II, 24).

El término república se emplea en ocasiones diferenciándolo de otras formas de organización política: porque con las armas se defienden las repúblicas, se conservan los reinos... (I, 38); ... que uno sólo no puede afrentar a reino, provincia, ciudad, república, ni pueblo entero (II, 27). En otras, sin embargo, se utiliza de forma aislada: república bien ordenada (I, 22); repúblicas bien concertadas (II, 27).

\section{GOBIERNO Y ADMINISTRACIÓN DE JUSTICIA}

La tarea de Sancho como gobernador de la Insula de Barataria abre la oportunidad de contemplar múltiples e interesantes ideas sobre el propio gobierno en sí, así como también sobre la administración de la justicia, si bien debe tenerse en cuenta que el poder de Sancho es absoluto: asume personalmente los poderes militar, legislativo, ejecutivo y judicial (II, 32, 42, 45, 49, 51, 53 y 55). De destacar es lo que a continuación sigue.

Fija don Quijote las características para ser un buen gobernante no siendo por muchas experiencias... menester ni mucha habilidad ni muchas letras...; el toque está en que [los gobernadores] tengan buena intención y deseen acertar en todo, que nunca les faltará quien les aconseje y encamine en lo que han de hacer... (II, 32). Instruye a Sancho sobre los deberes, virtudes y cualidades que debe mostrar en su doble condición de juez y gobernador: las leyes deben ser las precisas y necesarias; también eficaces y realistas. Así, le aconseja: 
No hagas muchas pragmáticas, y si las hicieres, procura que sean buenas, y sobre todo que se guarden y se cumplan, que las pragmáticas que no se guardan lo mismo es que si no lo fuesen... (II, 51).

Nunca te guíes por la ley del encaje [resoluciones arbitrarias del juez, o dictadas con prevaricación por lo que a él se le ha "encajado en la cabeza"] que suele tener mucha cabida con los ignorantes que presumen de agudos.

Hallen en ti más compasión las lágrimas del pobre, pero no más justicia que las informaciones [alegaciones] del rico.

Procura descubrir la verdad por entre las promesas y dádivas del rico como por entre los sollozos e importunidades del pobre.

Cuando pudiere y debiere tener lugar la equidad, no cargues todo el rigor de la ley al delincuente, que no es mejor la fama del juez riguroso que la del compasivo.

Si acaso doblares la vara de la justicia [si juzgas que no es oportuno aplicar el rigor de la ley] no sea con el peso de la dádiva, sino con el de la misericordia.

Cuando te sucediere juzgar algún pleito de algún tu enemigo aparta las mientes de tu injuria y ponlas en la verdad del caso.

No te ciegue la pasión propia en la causa ajena, que los yerros que en ella hicieres las más veces serán sin remedio, y si le tuvieren, será a costa de tu crédito, y aun de tu hacienda.

Si alguna mujer hermosa viniere a pedirte justicia, quita los ojos de sus lágrimas y tus oídos de sus gemidos, y considera de espacio la sustancia de lo que pide, si no quieres que se anegue tu razón en su llanto y tu bondad en sus suspiros.

Al que has de castigar con obras no trates mal con palabras, pues le basta al desdichado la pena del suplicio, sin la añadidura de las malas razones.

Al culpado que cayese debajo de tu jurisdicción considerale hombre miserable [digno de conmiseración] sujeto a las condiciones de la depravada naturaleza nuestra, y en todo cuanto fuere de tu parte, sin hacer agravio a la contraria, muéstrate piadoso y clemente, porque aunque los atributos de Dios son todos iguales, más resplandece y campea a nuestro ver el de la misericordia que el de la justicia (II, 42). 
En su corta etapa como gobernador, Sancho quedó no harto de pan ni de vino, sino de juzgar y dar pareceres y de hacer estatutos y pragmáticas (II, 53). En efecto, en cuanto a su labor legislativa -entre otras cosas, regulación del comercio del vino, del precio del calzado, los salarios de los criados y la mendicidad- él ordenó cosas tan buenas, que hasta hoy se guardan en aquél lugar, y se nombran "Las constituciones del gran gobernador Sancho Panza" (II, 51).

En la atañente como administrador de justicia es de destacar, entre otros pleitos (como el del "sastre o de las caperuzas" y el del "báculo"), el de la mujer presuntamente violada (todos en II, 45):

Una mujer acusa a un ganadero de haberla violado: este mal hombre [dice] me ha cogido en la mitad dese campo y se ha aprovechado de mi cuerpo como si fuera trapo mal lavado. El ganadero se defiende alegando que la mujer miente pues, dice, volvíame a mi aldea, topé en el camino a esta buena dueña, y el diablo, que todo lo añasca y todo lo cuece, hizo que yogásemos [yaciésemos] juntos; paguéle lo suficiente y ella, mal contenta, asió de mí y no me ha dejado hasta traerme a este puesto. Sancho pregunta al ganadero si lleva una bolsa con dinero y ante la respuesta afirmativa le ordena que se la de a la mujer que, contenta, sale del juzgado. De seguido Sancho le dice al ganadero que vaya tras la mujer y le quite la bolsa. Al rato volvieron ambos sin que el ganadero consiguiera el objetivo, de todo punto imposible, según la mujer la defendía y Sancho le pregunta a la mujer: ¿Y háosla quitado?. ¿Cómo quitar?, respondió la mujer. Antes me dejara yo quitar la vida que me quiten la bolsa... jotros gatos me han de echar a las barbas que no este desventurado y asqueroso! itenazas y martillos... no serán bastantes a sacármela de las uñas, ni aun garras de leones! Sancho devuelve la bolsa al ganadero y sentencia a la esforzada y no forzada del siguiente modo: Hermana mía, si el mismo aliento y valor que habeis mostrado para defender esta bolsa le mostráredes, y aun la mitad menos, para defender vuestro cuerpo, las fuerzas de Hércules no os hicieran fuerza. Andad con Dios, y mucho de enhoramala, y no pareis en todo esta ínsula ni en seis leguas a la redonda, so pena de doscientos azotes. La prostitución no era en la época considerada como pecado grave de ahí que más adelante, como se ha de ver, se reste importancia al delito de la alcahuetería y se proponga en definitiva la regulación del trato carnal.

La administración de justicia por Sancho como gobernador de la ínsula no agota los supuestos de actuaciones judiciales. Muy por el 
contrario, éstos son frecuentes en otros pasajes de la Obra que contemplan al propio don Quijote actuando como juez como por ejemplo en el episodio de los galeotes para procurarles su libertad y que tan malamente se lo agradecieron $(I, 22)$; o en el del maltrato por el rico labrador Juan Haldudo hacia su criado el joven pastor Andrés con sentencia "laboral", incluida una compensación de deudas, que lejos de ser cumplida propició una nueva paliza del labrador a su criado: y asiéndole del brazo le tornó a atar a la encina, donde le dio tantos azotes que le dejó por muerto. Con palpable burla al fin le desató y le dio licencia que fuese a buscar su juez para que ejecutase la pronunciada sentencia $(I, 4)$.

También se contempla el arbitraje como procedimiento para impartir justicia lo que estaba arraigado en las costumbres populares. Así por ejemplo para solventar el contencioso surgido por los destrozos que don Quijote causa en las figuras del retablo del maese Pedro, se procede al nombramiento del señor ventero y el gran Sancho... [como] mediadores y apreciadores [entre don Quijote y el maese] de lo que valen o podían valer las ya deshechas figuras (II, 45).

\section{DERECHO PENAL}

En el Capítulo referente a los galeotes $(I, 22)$ se pone de manifiesto que los castigos y las penas a los delincuentes son la consecuencia punible por los delitos cometidos. Así, al ver Sancho la cadena de galeotes, condenados a remar en los barcos de la armada real dice que es gente forzada del rey, que va a las galeras... gente que por sus delitos va condenada a servir al rey en las galeras de por fuerza. No sin cierta crítica e ironía se hace patente la extrema dureza y severidad de los castigos de la época. Así por ejemplo cien azotes y tres años de galeras al que robó una canasta de colar; cuatro años al condenado por alcahuete y hechicero y seis años también a galeras y doscientos azotes, al cuatrero.

Dos observaciones importantes a mi juicio en este contexto. La primera que se quiere restar relevancia penal a la práctica de la alcahuetería proponiendo su regulación por las autoridades: por solamente... alcahuete [dice don Quijote] no merecía él ir a bogar en las galeras... porque el ... de alcahuete, ... es oficio de discretos y necesarísimo en la república bien ordenada, y que no le debería ejercer sino gente muy bien nacida; y aun había de haber veedor y examinador de los tales, como lo hay de los demás oficios; recuérdese, como se dijo, que la prostitución no era considerada en la época pecado grave. La segunda observación que se 
anunciaba es la crítica que se hace del tormento para arrancar la confesión del reo. Así, un guarda de los galeotes le dice a don Quijote: A este pecador le dieron tormento y confesó su delito... y por haber confesado le condenaron... y... los demás ladrones... le maltratan y escarnecen porque confesó... porque dicen... que harta ventura tiene un delincuente que está en lengua su vida o su muerte, y no en la de testigos y probanzas... $Y$ yo lo entiendo así, respondió don Quijote.

De destacar por otra parte es la alusión a caracteres y rasgos fisonómicos, anatómicos y psicológicos como precursores de lo que mucho tiempo después daría lugar a la doctrina de la antropología criminal. Algunos ejemplos al respecto: sobre los galeotes, dice un guarda que, es gente que recibe gusto de hacer y decir bellaquerías. Del también galeote Ginés de Pasamonte se dice que, al mirar metía el un ojo en el otro un poco (I, 22), esto es bizqueaba señal inequívoca de traición y mal farío. De semejantes juicios antropológicos no se libra el bachiller Sansón Carrasco: ... gran socarrón... carirredondo, de nariz chata y de boca grande, señales todas de ser de condición maliciosa y amigo de donaires y de burlas... (II, 3); ni tampoco Reinaldo de Montalbán que era ancho de rostro, de color bermejo, los ojos bailadores y algo saltados... amigo de ladrones y de gente perdida (II, 1).

\section{DERECHO PRIVADO}

El derecho de propiedad está presente a lo largo de toda la obra. Pero don Quijote describe una situación utópica, un tiempo de felicidad natural en el que hubiese querido vivir: Dichosa edad y siglos dichosos... porque entonces los que en ella vivían ignoraban estas dos palabras de tuyo y mío. Eran en aquella santa edad todas las cosas comunes... Todo era paz entonces, todo amistad, todo concordia... (I, 11). Sin embargo tal situación contrasta con la realidad. Así le dice Sancho a don Quijote: tanto vales cuanto tienes, y tanto tienes cuanto vales. Dos linajes solos hay en el mundo, como decía una agüela mía, que son el tener y el no tener (II, 20).

La responsabilidad objetiva de don Quijote por daños se pone de manifiesto en el contencioso que mantuvo con el maese Pedro. Ante los daños causados por don Quijote en su retablo este le dice: ... por cumplir con mi profesión de Caballero andante quise dar ayuda y favor a los que huían, y con este buen propósito hice lo que habeis visto: si me ha salido al revés, no es culpa mía, sino de los malos que me persiguen; y 
con todo esto, deste mi yerro, aunque no he procedido de malicia, quiero yo mismo condenarme en costas: vea maese Pedro lo que quiere por las figuras deshechas, que yo me ofrezco a pagárselo luego, en buena y corriente moneda castellana (II, 26).

Y la posible responsabilidad penal y civil de don Quijote con la correlativa indemnización de daños y perjuicios por obligar el Caballero a que se abra la jaula de los leones, es puesta de manifiesto por el leonero [que] dijo a grandes voces: - Seánme testigos cuantos aquí están como contra mi voluntad y forzado abro las jaulas y suelto los leones, y de que protesto a este señor que todo el mal y daño que estas bestias hicieren corra y vaya por su cuenta, con más mis salarios y derechos [II, 17; la forma de la frase corresponde a la jerga de los documentos]. En otro pasaje: $Y$, así, desde ahora intimo a vuestra merced, señor escudero, que corra por su cuenta todo el mal y daño que de nuestra pendencia resultare, díjole Sancho a el del Bosque [II, 14; fórmula de escribanos empleada en las cartas requisitoriales civiles al aceptar el aplazamiento de un pleito].

Frecuentes y variadas alusiones al derecho de familia aparecen en la Obra. Se defiende la indisolubilidad del matrimonio. Dice al respecto don Quijote: la [compañía] de la propia mujer no es mercaduría que una vez comprada se vuelve o se trueca o cambia, porque es accidente inseparable [esto es, cualidad no necesaria pero si producida se une indisolublemente a la persona] que dura lo que dura la vida: es un lazo que, si una vez le echáis al cuello, se vuelve en el nudo gordiano, que si no le corta la guadaña de la muerte, no hay desatarle (II, 19; también I, 33 y II, 21).

Costumbre extendida era la celebración de matrimonios privados o en secreto -equivalentes al matrimonio sacramental- que prohibió el Concilio de Trento. Así, dice Dorotea, tomando don Fernando una imagen que en aquel aposento estaba la puso de testigo de nuestro desposorio; con palabras eficacísimas y juramentos extraordinarios me dio la palabra de ser mi marido... pronunciando una de las fórmulas más corrientes en esta clase de matrimonios: ves aquí te doy la mano de serlo tuyo, y sean testigos de esta verdad los cielos, a quien ninguna cosa se asconde, y esta imagen de Nuestra Señora que aquí tienes (I, 28; también I, 24).

Por otra parte, la Obra alude en varias ocasiones al alcance de la autoridad de los padres sobre la aprobación del matrimonio de los 
hijos (I, 51 y II, 19, por ejemplo) primando la libertad de elección de estos, pues como decía el tío de Marcela y decía muy bien, que no habían de dar los padres a sus hijos estado contra su voluntad (I, 12); y Dorotea: ellos [mis padres] me casarían luego con quien yo más gustase (I, 28). Pero la autoridad del marido sobre la mujer es indiscutible. Así, dice Teresa Panza a Sancho: pero otra vez os digo que hagáis lo que os diere gusto, que con esta carga nacemos las mujeres, de estar obedientes a sus maridos, aunque sean unos porros (II, 5; tontos, zotes).

Finalmente, la preocupación de la época por la educación de los hijos, se pone de manifiesto por don Quijote en su plática con el Caballero del Verde Gabán: Los hijos, señor, son pedazos de las entrañas de sus padres, $\mathrm{y}$, así se han de querer, o buenos o malos que sean, como se quieren las almas que nos dan vida. A los padres toca el encaminarlos desde pequeños por los pasos de la virtud, de la buena crianza y de las buenas y cristianas costumbres, para que cuando grandes sean báculo de la vejez de sus padres y gloria de su posteridad; y en lo de forzarles que estudien esta o aquélla ciencia, no lo tengo por acertado, aunque el persuadirles no será dañoso, y cuando no se ha de estudiar para pane lucrando [para ganarse la vida; el pan], siendo tan venturoso el estudiante que le dio el cielo padres que se lo dejen [el pan; esto es, rentas suficientes para vivir] sería yo de parecer que le dejen seguir aquella ciencia a que más le vieren inclinado (II, 16).

\section{DERECHO DEL TRABAJO}

Además de los relacionados con la iglesia, el ejército, la política o la administración de la justicia, en la Obra se alude a múltiples y variados trabajos y oficios de los sectores, entre otros, rural, artesano y de servicios, entre ellos el doméstico. Algunos minusvalorados 0 menospreciados; así, y a modo de ejemplo, don Quijote ve en la actividad que realiza Dulcinea la venganza de los encantadores: quieren quitarme la vida maltratando la de Dulcinea por quien yo vivo; ... la convirtieron en villana y ocupada en tan bajo ejercicio como es el de ahechar [limpiar] trigo (II, 32).

También al trabajo forzoso y al prestado en régimen de esclavitud: el de los galeotes, que como dice Sancho es trabajo de gente que por sus delitos va condenada a servir al rey en las galeras de por fuerza (I, 22); el de los cautivos del turco o del rey que [no] son de rescate e incluso estos últimos cuando se tarde su rescate... [porque] les hacen 
trabajar e ir por leña con los demás, que es un no pequeño trabajo (I, 40); y el de los vasallos negros en el país de la princesa Micomicona (I, 29).

La alusión a prestaciones de servicios asalariados es en ocasiones explícita. Así por ejemplo, el trabajo de leonero (II, 27); o el del ama de don Quijote como corrobora este al hacer testamento: y la primera satisfacción que se haga quiero que sea pagar el salario que debo del tiempo que mi ama me ha servido... (II, 74); o el del propio Sancho cuando le dice a don Quijote que en tiempos en los que servía... a Tomé Carrasco, ... dos ducados ganaba cada mes; amén de la comida (II, 28); salario, pues, en metálico y en especie. Asimismo -y contra la tradicional retribución mediante honorarios- el de Pedro Recio: Yo señor [le dice a Sancho gobernador] soy médico y estoy asalariado en esta ínsula (II, 47).

Constante a lo largo de la Obra, es la relación entre don Quijote caballero andante y amo, y Sancho Panza su escudero y criado. Constante asimismo es la discusión habida entre ambos sobre la naturaleza jurídica de la relación de los servicios prestados por Sancho al Caballero y su retribución (I, 18, 20; II, 7, 28, 74).

Sancho diferencia bien como pago de sus servicios entre salarios y mercedes. Quiere ver que aquellos se retribuyen con salario fijo, a tiempo en cómputo y devengo mensual; a sueldo en definitiva pues dice, no quiero estar a mercedes [como pretende don Quijote] que llegan tarde o mal o nunca (II, 7), esto es, a lo que su amo quiera darle voluntariamente a modo de premio, compensación, gratificación o recompensa: la gobernanza de la Insula Barataria. Como la discusión persiste, llega incluso Sancho a plantear la voluntaria extinción de su relación de servicios con su amo provocando la cólera de don Quijote que entre otras lindezas le llama prevaricador de las ordenanzas escuderiles de la andante caballería (II, 28) pues precisamente según éstas, a los escuderos se les remuneraba por mercedes y no con salarios. Pero el Caballero accede a pagar mediante salarios sin excluir las mercedes y el asunto, que no por lo dicho deja de ser en ningún momento controvertido, llega al Capítulo final de la Obra (II, 74) en el que don Quijote, próximo a su muerte, dicta sus últimas voluntades accediendo a lo tantas veces pedido por Sancho pero empecinado también en seguir manteniendo las mercedes: Iten, es mi voluntad que de ciertos dineros que Sancho Panza, a quien en mi locura hice mi escudero, tiene, que porque ha habido entre él y mí ciertas cuentas, y dares y tomares, quiero que no se le haga cargo dellos ni se le pida cuenta alguna, sino que si sobrare alguno, después de haberse pagado de lo que le debo, el restante sea suyo, que será bien 
poco, y buen provecho le haga; y si, como estando yo loco fui parte para darle el gobierno de la ínsula, pudiera agora, estando cuerdo, darle el de un reino, se le diera, porque la sencillez de su condición y fidelidad de su trato lo merece.

\section{EPÍLOGO}

José Mariano Llorente y Llorente, alumno de la Cátedra de Derecho Administrativo de la Universidad de Valladolid escribió un ensayo titulado "Algunas ideas del Quijote aplicadas a la doctrina fundamental de la administración"; obtuvo el primer premio en el curso académico 1903/1904 y fue publicado en Valladolid por la Imprenta y Librería de Jorge Monero, Acera 4 y 6 y Cascajares, 2, hace ahora algo más de un siglo. Leopoldo de Michelena era en aquél entonces el titular de la Cátedra. A modo de Prólogo al trabajo reflexiona sobre el "Propósito de la Biblioteca de Derecho Administrativo". Todo lo que allí se dice es más que interesante, pero de destacar son los siguientes párrafos:

"No es posible exigir que los alumnos, además del importe de las matrículas y de los dispendios á que á la generalidad obliga la permanencia en la capital universitaria, sufraguen los gastos de adquisición de las obras necesarias para la formación de una Biblioteca especial para cada Cátedra... La Biblioteca debe estar unida á la misma cátedra". "Ante esta necesidad... me he constituido en el propósito de intentar la formación de una pequeña Biblioteca para la cátedra de Derecho Administrativo que explico... Aun dedicando á este propósito como he dedicado, una parte del pequeño haber con que se recompensan por el Estado los servicios del Catedrático; aun favorecido, como lo he sido, por el apoyo oficial y el de algún particular, con la entrega de libros y colecciones, me faltaban recursos para completar mi propósito. Para lograrlos comienzo la publicación de esta Biblioteca". El producto de la venta de los libros por ésta publicación se aplicará por tanto a la adquisición de libros pues, "nada más justo, por consiguiente, que á la cátedra vengan a beneficiar nuestros esfuerzos". Pero, en el epílogo titulado "Advertencias" se dice: "la Comisión administrativa de la Biblioteca [formada por Leopoldo de Michelena y una comisión de alumnos] ha acordado que, por excepción y dado el carácter de esta obra, se destine el 20 por 100 de los productos en metálico de esta $1^{\text {a }}$ edición, al homenaje que á Miguel de Cervantes Saavedra se le tributa, con motivo del tercer centenario de la publicación del Quijote. La cantidad á que 
ascienda el importe de dicho 20 por 100, se consignará á nombre de D. Mariano de Cavia, iniciador del Centenario, para que la aplique al concepto que juzgue preferente en aquel homenaje".

La tasa para la primera parte del Quijote fue fijada en doscientos noventa maravedís y medio, en que se ha de vender en papel [sin encuadernar] y [los señores del Consejo de la Cámara del Rey] dieron licencia para que a este precio se pueda vender, y mandaron que esta tasa se ponga al principio de dicho libro, y no se pueda vender sin ella. Para la segunda parte, también en papel, el precio fijado fue de doscientos y noventa y dos maravedís; y mandaron que esta tasa se ponga al principio de cada volumen de dicho libro, para que se sepa y entienda lo que por él se ha de pedir y llevar, sin que se exceda en ello en manera alguna (Tasa I y II). Cada parte costó pues algo más de ocho reales. Como referencia, el año en el que se publicó la primera parte, en Castilla la Nueva un pollo costaba 63 maravedís; una gallina 127; una docena de huevos 63 y una resma de papel de escribir 28. Seguramente Cervantes hombre culto y amante de los libros -como soy aficionado a leer aunque sean los papeles rotos de las calles- hubiera contribuido con el 20 por 100 del producto de la venta de su Quijote a la formación de la biblioteca de la Cátedra de Derecho Administrativo de la Universidad de Valladolid. Sirva también lo señalado como referencia de lo que Cervantes podía adquirir o comprar en comida y alimentación por cada ejemplar vendido.

Vale (Prólogo I y II, 74). 